\title{
Biosynthesis of silver nanoparticles by marine bacterium, Idiomarina sp. PR58-8
}

\author{
SACHIN SESHADRI, ANUPAMA PRAKASH and MEENAL KOWSHIK* \\ Birla Institute of Technology \& Science Pilani- K K Birla Goa Campus, Zuarinagar, Goa 403 726, India
}

\begin{abstract}
Metal-tolerant microorganisms have been exploited in recent years to synthesize nanoparticles due to their potential to offer better size control through peptide binding and compartmentalization. In this paper, we report the intracellular synthesis of silver nanoparticles (SNPs) by the highly silver-tolerant marine bacterium, Idiomarina sp. PR58-8 on exposure to $5 \mathrm{mM}$ silver nitrate. SNPs were characterized by UV-visible spectrophotometry, X-ray diffraction (XRD), scanning electron microscopy (SEM) and transmission electron microscopy (TEM). UV-visible absorption scan of a $48 \mathrm{~h}$ culture exposed to $5 \mathrm{mM}$ silver nitrate revealed a broad peak at $450 \mathrm{~nm}$ indicative of the surface plasmon resonance of SNPs. XRD analysis confirmed the presence of elemental silver and the crystallite size was calculated to be $25 \mathrm{~nm}$ using Scherrer formula. The average particle size as per TEM analysis was found to be $26 \mathrm{~nm}$. Metal stress is known to induce the production of non-protein thiols (NP-SHs) which sequester metal ions. In this study, the production of NP-SHs was followed from $6-48 \mathrm{~h}$, wherein it was observed that the NP-SH levels in the silver-exposed culture were consistently higher (261\% on an average) than in the unexposed culture.
\end{abstract}

Keywords. Nanoparticles; silver; marine; biosynthesis; thiols.

\section{Introduction}

Synthesis of nanoparticles has attracted a lot of attention due to their unusual optical (Krolikowska et al 2003), photoelectrochemical (Chandrasekharan and Kamat 2000) and electronic (Peto et al 2002) properties. Both unicellular and multicellular organisms have been known to produce inorganic materials either intra- or extra-cellularly (Mann 1995). Microorganisms ranging from bacteria to fungi have been used in recent years to develop non-toxic and environment friendly methods to synthesize nanoparticles (Kowshik et al 2002; Bhattacharya and Rajinder 2005). Methods of nanoparticle synthesis using microbes offer better size control through compartmentalization in the periplasmic space and vesicles. The rate of intracellular particle formation and therefore, size of the nanoparticles could, to an extent, be manipulated by controlling parameters such as $\mathrm{pH}$, temperature, substrate concentration and time of exposure to substrate (Gericke and Pinches 2006). Additionally, nanoparticles synthesized by microorganisms tend to be stabilized by peptides such as phytochelatins, thus preventing aggregation (Kang et al 2008). These short peptides are synthesized in response to heavy metal stress and have been implicated as a universal mechanism to sequester metal ions in bacteria (Pages et al 2008), fungi (Guimaraes-Suares et al 2007) and plants (Cobbett 2000).

\footnotetext{
*Author for correspondence (meenal@goa.bits-pilani.ac.in)
}

SNPs find applications in nonlinear optics, spectrally selective coating for solar energy absorption, biolabelling (Joerger et al 2000), intercalation materials for electrical batteries, as optical receptors, catalyst in chemical reactions, antibacterial capacities (Duran et al 2005) and in vitro inhibition of HIV-1 (Elechiguerra et al 2005). Silver nanoparticles (SNPs) have been biosynthesized using several terrestrial microorganisms such as Fusarium oxysporum (Senapati et al 2004), a yeast strain MKY3 (Kowshik et al 2003), Psuedomonas stutzeri AG259 (Joerger et al 2000), Lactobacillus sp. (Nair and Pradeep 2002), Escherichia coli (Gurunathan et al 2009) etc. Marine environments could be a good source of metal tolerant microorganism as metals are continuously released into the marine environments by volcanoes, natural weathering of rocks and also by numerous anthropogenic acitivities, such as mining, combustion of fuels, industrial and urban sewage and agricultural practices. Recently, they are being explored as potential sources of metal tolerant microorganisms with the ability to synthesize metallic nanoparticles (Agnihotri et al 2009). SNPs have been synthesized using marine fungi (Kathiresan et al 2009), marine cyanobacteria (Ali et al 2011) and marine algal extracts (Venkatpurwar and Pokharkar 2011). However, there are no reports on SNP synthesis by marine bacteria. In this paper, we report the synthesis of SNPs by a marine bacterium, Idiomarina sp. PR58-8. This is also the first report on metal tolerance of Idiomarina genus. This bacterium synthesized SNPs when silver is added at the time of inoculation unlike the terrestrial bacteria, wherein silver was added in the mid-log phase of growth. 


\section{Materials and methods}

\subsection{Culture isolation and identification}

The bacterial culture used in this study was isolated from soil samples at the banks of the Mandovi River in Goa, India. The soil was collected in sterile containers and stored at $4{ }^{\circ} \mathrm{C}$. The soil $(1 \mathrm{~g})$ was suspended in $100 \mathrm{ml}$ of saline and agitated at $170 \mathrm{rpm}$ for $30 \mathrm{~min}$. The sample was then appropriately diluted and plated on Zobell Marine 2216 Agar. The plates were incubated at $30^{\circ} \mathrm{C}$ for $24 \mathrm{~h}$ and the colonies obtained were purified by re-streaking on the isolation medium. Purified bacterial culture was identified based on sequencing of the 16S rDNA region. Briefly, bacterial universal primers, $27 \mathrm{~F}$ and $1429 \mathrm{R}$ were used against the genomic DNA template and PCR was performed. The amplified 16S rDNA fragments were sequenced. The sequence data was aligned using ClustalX (version 2.0.12) and analysed to find the closest homologs for the microbe. The phylogenetic tree was prepared using NJ-plot.

\subsection{Silver resistance study}

The silver resistance study was performed by growing the Idiomarina sp. PR58-8 in Zobell Marine Broth 2216 containing $0.1 \mathrm{mM}$ of silver nitrate. The flasks were incubated for $24 \mathrm{~h}$ and the culture was transferred to fresh medium containing a higher concentration of the metal salt. A concentration range of 0.1 to $9 \mathrm{mM}$ was used to determine the tolerance levels. Elemental analysis was done using atomic absorption spectrophotometer, Shimadzu AA-6300.

\subsection{SNP synthesis and characterization}

Idiomarina sp. PR58-8 was grown in Zobell Marine Broth 2216 containing $5 \mathrm{mM}$ silver nitrate for $48 \mathrm{~h}$ under agitation at $120 \mathrm{rpm}$. The optical absorbance measurements of the culture growing in $5 \mathrm{mM}$ silver nitrate were taken on a UV visible spectrophotometer (Shimadzu UV 2450) in the range 200-800 nm. Cell pellets obtained from $48 \mathrm{~h}$ cultures were washed with deionized water and lyophilized. XRD measurements of the SNPs were taken on a Rigaku Miniflex from 20$80^{\circ}$ and the scan speed was $0 \cdot 2 / \mathrm{min}$ using a $\mathrm{Cu}-\mathrm{K} \alpha$ radiation of wavelength, $1.5408 \AA$. The crystallite size was calculated using Scherrer's equation,

$$
D=k \lambda / B \cos \theta,
$$

where $D$ is the crystallite diameter in $\AA, k$ the shape constant $(0.9), \lambda$ the $\mathrm{X}$-ray $(\mathrm{Cu} \mathrm{K} \alpha)$ wavelength in $\AA, \theta$ the diffraction angle and $B$ (in radian) is the half width measured for the XRD peak. Transmission electron microscopy (TEM) was performed using Phillips CM 200 electron microscope. Lyophilized cell pellet was cast on carbon coated copper grid and observed under TEM. Scanning electron microscopy and energy dispersive analysis of X-rays (SEM-EDAX) of the dried cell pellets was carried out on a JEOL JSM 6360 LV.

\subsection{Quantitation of thiols}

The concentration of T-SH and NP-SH was determined with 5, 5'-dithio-bis (2-nitrobenzoic acid) (DTNB; Sigma) according to Sedlak and Lindsay (1968). For T-SH assay, $50 \mu \mathrm{L}$ aliquots of the cell-free extracts were mixed with $150 \mu \mathrm{L}$ of $0 \cdot 2 \mathrm{M}$ Tris, $\mathrm{pH} 8 \cdot 2,10 \mu \mathrm{L}$ of $0 \cdot 01 \mathrm{M}$ DTNB and $790 \mu \mathrm{L}$ of absolute methanol (Merck). After $15 \mathrm{~min}$, the mixtures were centrifuged $(3000 \mathrm{~g}, 15 \mathrm{~min})$ and the absorbance was measured at $412 \mathrm{~nm}$ (Shimadzu UV-2450 UV/VIS Spectrometer) against a reagent blank, using reduced glutathione as standard. To determine NP-SH, aliquots of $500 \mu \mathrm{L}$ of the cell-free extracts were mixed with $400 \mu \mathrm{L}$ of milli-Q water and $100 \mu \mathrm{L}$ of $50 \%$ trichloroacetic acid (Merck). The mixtures were gently shaken for $12 \mathrm{~min}$ and centrifuged ( $3000 \mathrm{~g}, 15 \mathrm{~min})$. Subsequently, $200 \mu \mathrm{L}$ of the supernatant was mixed with $400 \mu \mathrm{L}$ of $0.4 \mathrm{M}$ Tris, $\mathrm{pH} 8.9$ and $10 \mu \mathrm{L}$ of $0.01 \mathrm{M}$ DTNB and absorbance was measured within 3 min of DTNB addition. The concentration of protein bound thiols (PB-SH) was calculated by subtracting the $\mathrm{NP}-\mathrm{SH}$ from T-SH concentrations.

\section{Results and discussion}

During the screening of microorganisms for synthesis of nanoparticles, we obtained a marine bacterium, Idiomarina sp. PR58-8 that synthesized SNPs intracellularly. Based on

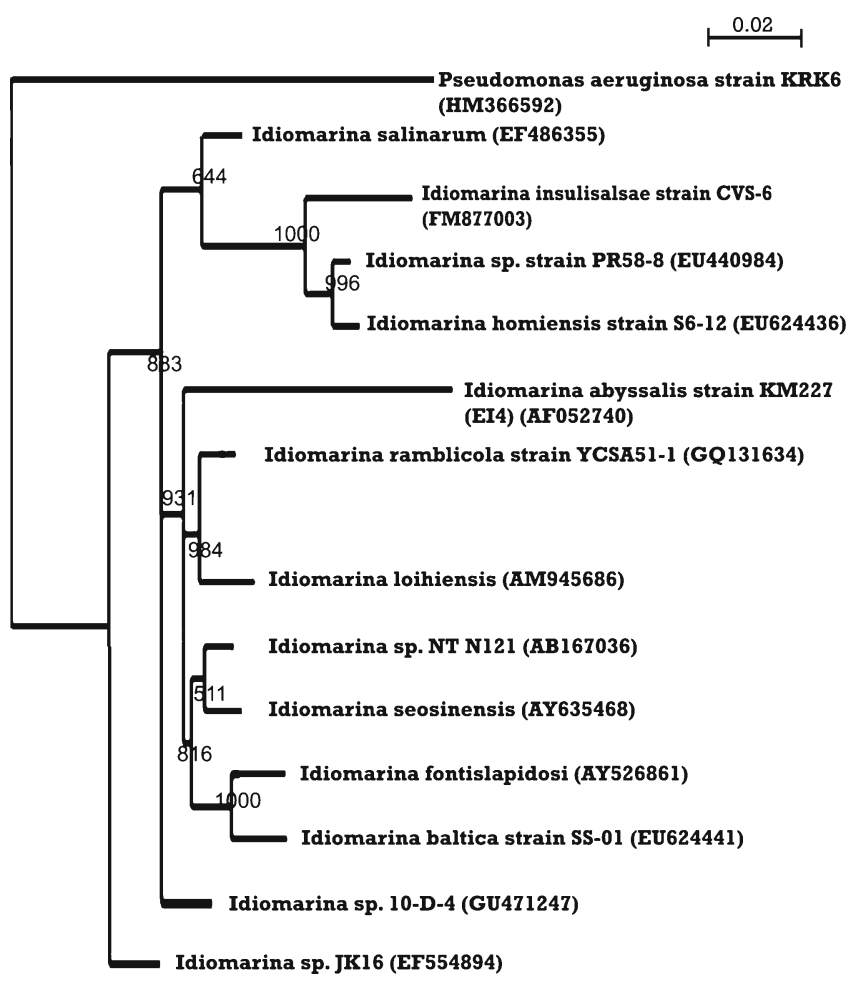

Figure 1. Phylogenetic position of marine bacterium in Idiomarina genus using NJ plot. The tree was rooted using Pseudomonas aeruginosa strain KRK6 as the outgroup. Bootstrap values from 1000 samplings are shown near the branches. 
nucleotide homology and phylogenetic analysis (figure 1), the bacterium was identified to be Idiomarina sp. PR58-8 (GenBank Accession Number EU440984). Nearest homolog was found to be Idiomarina homiensis. Salt was found to be an obligate requirement and a minimum of $1 \% \mathrm{NaCl}$ was required for growth. The culture could tolerate up to $15 \% \mathrm{NaCl}$ which is similar to the levels of salt tolerance reported for Idiomarina abyssalis KM227 and Idiomarina zobelli KMM231 (Ivanova et al 2000).

This bacterium was found to tolerate up to $7 \mathrm{mM}$ of silver nitrate in Zobell Marine Broth 2216 and accumulated more than $90 \%$ of silver intracellularly. Idiomarina sp. PR58-8 grown on liquid media containing silver salt turned brownish-black after $48 \mathrm{~h}$ indicative of silver accumulation by the biomass while the unexposed culture was golden yellow in colour (figure 2). Characterization of the intracellularly accumulated silver revealed the presence of SNPs. UVvisible absorption scan of the $48 \mathrm{~h}$ culture grown in $5 \mathrm{mM}$ silver nitrate revealed a broad peak at $450 \mathrm{~nm}$ due to the surface plasmon resonance of SNPs (figure 3). Observation of a broad surface plasmon peak in the $400-450 \mathrm{~nm}$ range is a characteristic of SNPs (Kowshik et al 2003). XRD analysis of lyophilized cell pellets is shown in figure 4 . The peaks at Bragg angles of $38.11^{\circ}, 44.27^{\circ}$ and $64.42^{\circ}$ correspond to elemental silver (3C-syn) in the ICDD. The crystallite size as determined by Scherrer formula was determined to be $25 \mathrm{~nm}$. Due to the high salt content of the system, $\mathrm{NaCl}$ peaks were also seen. XRD of lyophilized Zobell Marine Broth 2216 containing $5 \mathrm{mM}$ silver nitrate did not show any of the signature silver peaks. TEM micrographs showed that most of the particles were in the $26 \mathrm{~nm}$ size range (figure 5). Energy dispersive X-ray analysis (EDAX) showed presence of silver

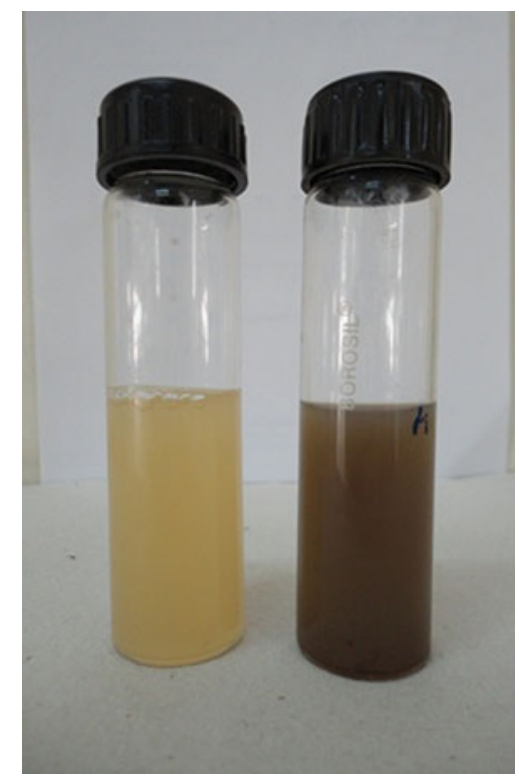

Figure 2. Colour change from golden yellow to brownish-black observed when Idiomarina sp. PR58-8 is grown in $5 \mathrm{mM}$ silver nitrate after $48 \mathrm{~h}$.

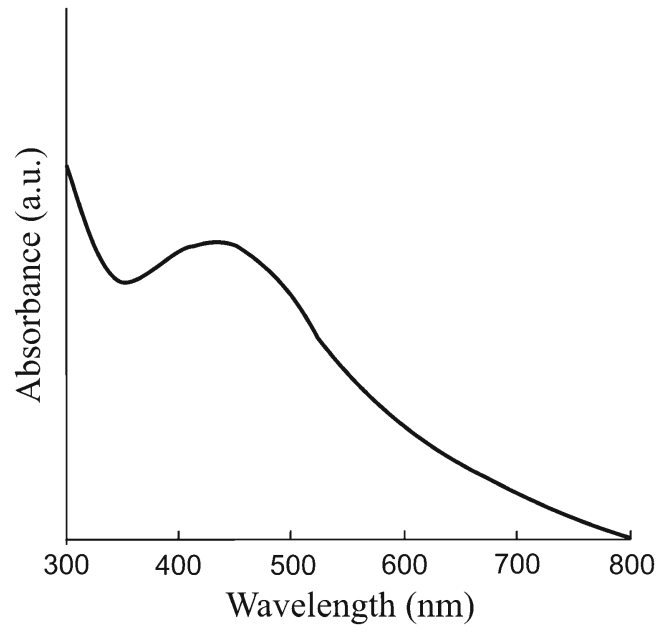

Figure 3. UV-visible absorbances scan of Idiomarina sp. PR58-8 growing in $5 \mathrm{mM}$ silver nitrate after $48 \mathrm{~h}$.

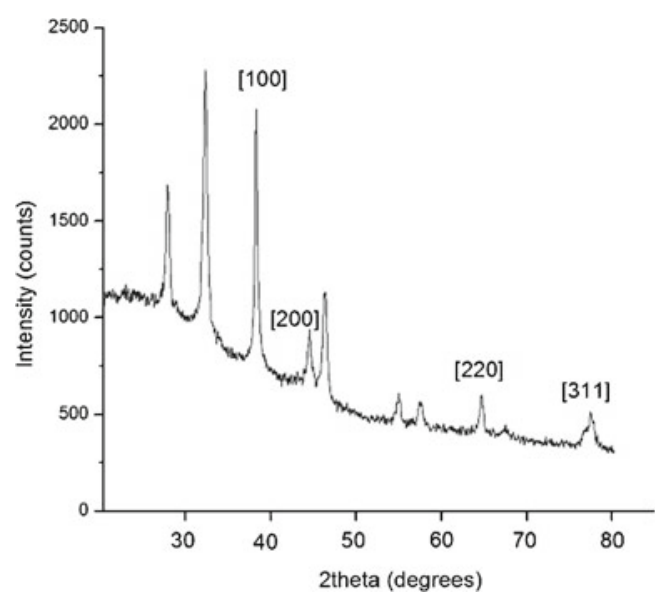

Figure 4. XRD of Idiomarina $s p$. PR58-8 grown in presence of $5 \mathrm{mM}$ silver nitrate for $48 \mathrm{~h}$.

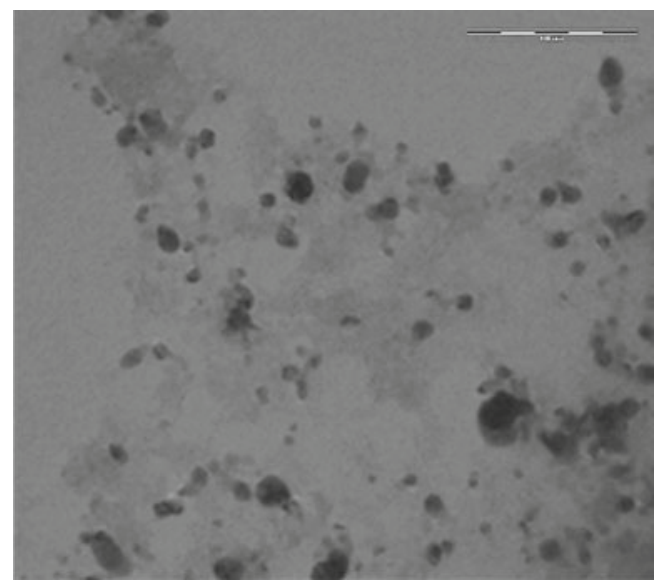

Figure 5. TEM image of lyophilized cells of Idiomarina sp. PR58-8 grown in presence of $5 \mathrm{mM}$ silver nitrate for $48 \mathrm{~h}$. 

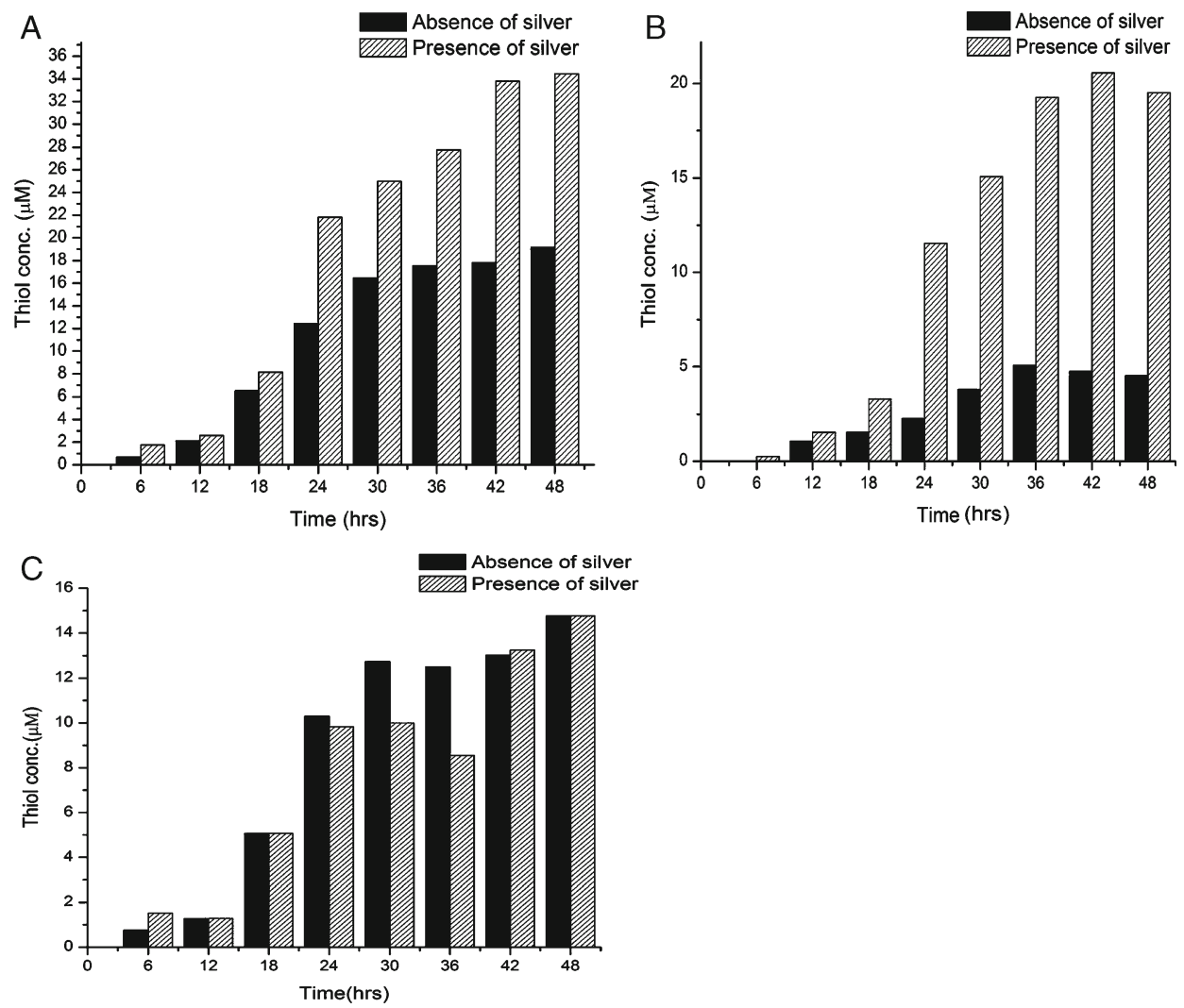

Figure 6. Comparison of intracellular thiol levels for cells grown in presence and absence of silver nitrate with respect to time. Levels of (a) total thiols, (b) non-protein thiols and (c) protein-bound thiols.

which constituted up to $6 \%$ of the sample. The other elements present were $\mathrm{C}, \mathrm{O}, \mathrm{N}$ and $\mathrm{S}$ which were constituents of the microbial cells.

Bacteria respond to oxidative stresses such as exposure to heavy metals by inducing the intracellular expression of thiol peptides which sequester the metal ions (Pages et al 2008). Capping of nanoparticles by thiol peptides is known to occur in the biosynthetic system (Kang et al 2008). Hence, the intracellular thiol response of Idiomarina sp. PR58-8 to $2 \mathrm{mM}$ silver nitrate was studied over a period of $48 \mathrm{~h}$. It was observed that the silver-exposed culture responded to the silver stress by increasing its intracellular levels of T-SH (figure $6 \mathrm{a}$ ). This increase was prominent after $18 \mathrm{~h}$ of growth, averaging an increase of $70.5 \%$ over the unexposed culture (control). The increase in T-SHs could largely be attributed to the induction of NP-SHs as shown in figure $6 \mathrm{~b}$. The NP-SH levels showed a $261 \%$ increase on an average over the control. An increase in NP-SH levels in bacteria and fungi is reported to occur in response to metal stress (Guimaraes-Suares et al 2007; Pages et al 2008). The levels of PB-SHs did not change significantly in response to silver and were found to be equal or lower than that observed for cells grown in the absence of silver (figure 6c). The lower levels of PB-SHs in exposed cultures could be explained by a sulfur shift in the focus of the bacterial proteome towards synthesis of glutathione. A similar trend was observed for cadmium-exposed yeast wherein the yeast adjusts its proteome by reducing the synthesis of sulfur-rich proteins and diverting most of the assimilated sulfur towards glutathione synthesis, thereby reducing $\mathrm{PB}-\mathrm{SH}$ levels and increasing levels of NP-SHs (Fauchon et al 2002). Thus, NP-SHs appear to play a key role in silver tolerance of Idiomarina $s p$. PR58-8.

\section{Conclusions}

Here we report the synthesis of intracellular SNPs by a marine bacterium, Idiomarina $s p$. PR58-8 which was found to be highly silver tolerant. This is the first report on heavy metal resistance and synthesis of metal nanoparticles in the Idiomarina genus. An advantage exhibited by the marine bacterium, Idiomarina sp. PR58-8 is that the marine bacterium synthesizes SNPs when silver is added at the time of inoculation as against terrestrial bacteria such as Lactobacillus $s p$. and Escherichia coli wherein silver was added in the mid-log phase of growth. This could be attributed to the high silver-tolerance of Idiomarina sp. PR58-8 and eliminates the requirement of growth phase monitoring during synthesis of SNPs. UV-visible absorbance scan of the $48 \mathrm{~h}$ culture from $300-800 \mathrm{~nm}$ revealed a broad peak at $450 \mathrm{~nm}$, a characteristic of SNPs. XRD of lyophilized cell pellets 
obtained from $48 \mathrm{~h}$ cultures corresponded to silver (3C-syn) in the ICDD. TEM showed presence of SNPs in the $26 \mathrm{~nm}$ size range which upon purification could be applied in biolabelling, antimicrobial coatings etc. The bacterium was found to respond to silver stress by inducing the expression of NPSHs at extremely high levels (261\% on average) over the control, peaking at $42 \mathrm{~h}$. Thus Idiomarina sp. PR58-8 is a promising microorganism for metal accumulation and metal nanoparticle synthesis.

\section{Acknowledgements}

(MK) thanks DST, India, for financial support (SR/FT/L94/2005). The authors thank Dr Rahul Mohan, NCAOR, Goa, for helping with the SEM-EDAX measurements and SAIF, IIT Bombay, for TEM analysis. (SS) thanks BITS Pilani, K K Birla Goa campus, Goa, for a Research Fellowship.

\section{References}

Agnihotri M, Joshi S, Kumar A R, Zinjarde S and Kulkarni S K 2009 Mater. Lett. 631231

Ali D M, Sasikala M, Gunasekaran M and Thajuddin N 2011 Dig. J. Nanometer. Bios. 6385

Bhattacharya D and Rajinder G 2005 Crit. Rev. Biotechnol. 25 199

Chandrasekharan N and Kamat P V 2000 J. Phys. Chem. B104 10851

Cobbett C S 2000 Curr. Opin. Plant Biol. 3211
Duran N, Marcato P D, Alves O L, Souza G I and Esposito E 2005 J. Nanobiotechnol. 38

Elechiguerra J L, Burt J L, Morones J R, Camacho-Bragado A, Gao X, Lara H H and Yacaman M J 2005 J. Nanobiotechnol. 293

Fauchon M et al 2002 Mol. Cell. 9713

Gericke M and Pinches A 2006 Hydrometallurgy 83132

Guimaraes-Suares L, Pascoal C and Cassio F 2007 Ecotoxicol. Environ. Saf. 6636

Gurunathan S, Lee K, Kalishwaralal K, Sheikpranbabu S, Vaidyanathan R and Eom S 2009 Biomaterials 306341

Ivanova E P et al 2000 Int. J. Syst. Evol. Microbiol. 50201

Joerger R, Klaus T and Granqvist C G 2000 Adv. Mater. 12 407

Kang S, Bozhilov K N, Myung N V, Mulchandani A and Chen W 2008 Angew. Chem. Int. Ed. 475186

Kathiresan K, Manivannan S, Nabeel M A and Dhivya B 2009 Colloids Surf. B71 133

Kowshik M, Deshmukh N, Vogel W, Urban J, Kulkarni S K and Paknikar K M 2002 Biotechnol. Bioeng. 78583

Kowshik M, Ashtaputre S, Kharrazi S, Vogel W, Urban J, Kulkarni S K and Paknikar K M 2003 Nanotechnology 1495

Krolikowska A, Kudelski A, Michota A and Bukowska J 2003 Surf. Sci. 532227

Mann S 1995 J. Mater. Chem. 5935

Nair B and Pradeep T 2002 Cryst. Growth Des. 2293

Pages D, Rose J, Conrod S, Cuine S, Carrier P, Heulin T and Achouak W 2008 PLoS ONE 3 e1539

Peto G, Molnar G L, Paszti Z, Geszti O, Beck A and Guczi L 2002 Mater. Sci. Eng. 1995

Sedlak J and Lindsay R H 1968 Anal. Biochem. 25191

Senapati S, Mandal D, Ahmad A, Khan M I, Sastry M and Kumar R 2004 Indian J. Phys. A78 101

Venkatpurwar V and Pokharkar V 2011 Mater. Lett. 65999 